\title{
A Behavior-Centric Concept for Engineering Education in New Product Development
}

\author{
Jan Behrenbeck ${ }^{1}$, Nuno Miguel Martins Pacheco ${ }^{2}$, Bilal Tariq ${ }^{3}$, Markus Zimmermann ${ }^{4}$ \\ Technical University Munich \\ 1 jan.behrenbeck@tum.de \\ 2 martins.pacheco@tum.de \\ ${ }^{3}$ bilal.tariq@tum.de \\ 4 zimmermann@tum.de
}

\begin{abstract}
This paper addresses the need for novel formats in engineering education preparing students to create value. Following the approach of constructive alignment, it proposes an educational concept for a university course. Therefore, it first consolidates requirements from literature specifying the desired qualification of future engineers in New Product Development contexts. It then derives ten learning outcome statements for a course. The statements specify desirable student behavior targeting the proposed requirements for future engineers. As learning is constructed by what activities students carry out, learning activities and course elements are systematically derived from the course goals sourcing know-how from successfully established teaching concepts and the author's experience with hands-on teaching formats. The final course framework comprises an educational part, specifying course parameters and elements such as duration, team roles or coaching strategy. It also comprises a methodological part, specifying a human-centered prototyping methodology that guides students during the problem-solving process. The parts work hand in hand and seek to provide a safe environment while pushing students to show, experience, and train the desired behavior. The result is a ten-day makeathon in which students from various disciplines form interdisciplinary teams, identify and understand real world problems, iteratively prototype and test ideas, and develop minimum viable products considering their solutions' desirability, feasibility and viability. Key factors to push for commitment and results are intensity, autonomy, and communication. The framework is employed and tested within the format Think.Make.Start. at Technical University of Munich with students from different disciplines $(n=41)$. The student's learning progress is assessed by coaches observing and rating the performance of all teams each day through a questionnaire regarding the ten behavioral indicators. While the preliminary test suggests that the concept successfully fosters the desired behavior, it identifies the need for further research in assessing students' behavioral competencies objectively and individually in order to scientifically evaluate their learning progress.
\end{abstract}

Keywords: design teams, value driven design, new product development, entrepreneurship, design education 


\section{Introduction}

\section{Expected Changes in Work Environments}

Innovation and entrepreneurship have not only experienced an immense increase in public attention but have also been proven as driving factors for increased economic growth and wealth (van Stel, Carree, \& Thurik, 2005, p. 320). At the same time, global trends such as technological progress, globalization or demographic change have been shaping the work environment (World Economic Forum, 2016, p. 3). Volatility, uncertainty, complexity, and ambiguity (VUCA) are likely to dominate working conditions in the future (Bennett \& Lemoine, 2014). This has changed the requirements towards the profile of future employees. Prognoses for skills of future workers show an increase in the demand for cognitive skills such as creativity, logical reasoning and problem sensitivity (World Economic Forum, 2016, p. 27). At the same time, new jobs will require a lifelong learning attitude for the employee to be able to constantly adapt to new environments and collaborate with people from different disciplines and levels of hierarchy (World Economic Forum, 2016, p. 32).

\section{The Effect on required Job Profiles of Future Engineers}

As many engineers are closely involved in the creation of new technologies and innovations on one side, and massively employ these technologies on the other side, they are especially affected (National Academy of Engineering, 2004, p. 23). Besides technical competences and the underlying domain-specific mathematical and scientific knowledge, engineers need to be able to manage complexity, work in interdisciplinary teams and understand interrelations from a systems perspective including both technical and user requirements (National Academy of Engineering, 2004, p. 34, Crawley et al., 2011). Many of these skills are currently associated with entrepreneurs (Institute for the Future \& Dell Technologies, 2017, p. 15). Developing a set of skills, attitudes and ways of thinking that exceed the current engineering skills and knowhow takes time and can be tackled during higher education. Not every future engineer has to be an entrepreneur but they will need to know how to think in complex, dynamic and innovative environments (World Economic Forum, 2016, p. 27).

\section{Recent Developments in Engineering Education}

Influencing student behavior and mindset through entrepreneurial education and integrating it into classical engineering education curriculum is an approach educators and top universities around the globe have begun to understand and include, also in their research (Gemino, Roche, \& Lubik, 2018; Lackéus, 2015; Rae \& Melton, 2016). This holds especially for the United States of America (Yoder, Kleine, Carpenter, \& Fry, 2013, p. 2). In Europe there are plans to further increase the effort of integrating the teaching and especially the practice of these cognitive skills and the matching attitudes and behaviors in order to reach the demand for highly skilled and competent engineers.

While some courses have been established in a bottom-up approach, continuously trying to improve aspects of the courses and increase the popularity among students, they lack a systematic teaching concept. Moreover, there is not yet one common teaching approach that is accepted and uniformly used within the community which shows the need for new frameworks trying to systematically fill the gap in engineering education.

The next chapter provides an incomplete benchmark of entrepreneurial approaches in engineering education. Chapter 3 explains the methodological approach of this work. Chapter 4 and 5 introduces the derived learning outcomes and proposes the educational concept. Chapter 6 and 7 present an implementation and evaluation of the framework at TUM and discusses the implications for future research. 


\section{Benchmark: Entrepreneurial Approaches in Engineering Education}

\section{Entrepreneurial Education}

In comparison to other learning-by-doing approaches such as project-based learning or problem-based learning, entrepreneurial education incorporates most aspects that are relevant in training for VUCA environments (Lackéus, 2015, p.16). Entrepreneurial education bases on the concept that educational assignments trigger emotional events, situations and activities which in turn develop entrepreneurial competencies.

There are many traditional courses in business schools that focus on teaching entrepreneurship but do not encourage entrepreneurial thinking and acting. Although there are concepts for new curricula considering such requirements like the CDIO Syllabus V2, using entrepreneurial approaches in engineering education has not been established across all universities (Crawley et al., 2011). Some courses however have attracted attention during the last years by consequently employing entrepreneurial approaches in non-business fields.

\section{Example Courses}

One of the most popular and oldest courses on NPD is the course ME310 Design Innovation at Stanford University, in which students from different disciplines are taught to use Design Thinking methods to solve problems provided by industry partners. Through the course of the project, students learn, apply, and experience the Stanford Design Innovation Process and many of its tool sets (Leifer, 2012). The focus is on the application of methods. According to the classification scheme by Lackéus ME310 can be classified as a value creation course. (Lackéus, 2015, p.23) Based on the ME310 concept a global network of around 25 institutions called SUGAR has been established in 2008 to connect universities, companies and students and enable collaborative projects.

In recent years DTU Copenhagen has started new courses on entrepreneurship and engineering such as Xtech Entrepreneurship, which focuses on entrepreneurship with hardware products and methods coaching, but also entrepreneurial engineering courses such as Design Mechatronics, which provides prototyping coaching in a hands-on style, classifying it as a creation course (Lackéus, 2015, p.23).

A novel initiative is starting in 2020 at Imperial College London setting up interdisciplinary group projects for more than 300 students per year.

The Technical University of Munich (TUM) has already started to tackle the current challenge in 2015 by introducing additional elements to classical engineering education. One of the courses introduced was Think. Make. Start. (TMS). The course traditionally aims at students applying their domain-specific know-how in interdisciplinary teams to work on real-life problems and develop matching solutions. The course allows students from all faculties to engage in New Product Development and interact with students outside of their domains. Although TMS has been a success so far and has been adopted at other universities and in industry, it has been lacking a clear definition of learning outcomes and a systematic review of the internal structure as it has always been continuously extended without a top-down strategy. The current framework focuses on introducing and applying a methodology for product development called TAF in a makeathon format but does not ensure that the participants are able to develop a sustainable behavior alteration. (Böhmer, 2016)

According to the classification scheme by Lackéus Think. Make. Start. can be classified as a venture creation course (Lackéus, 2015, p.23).

\section{A missing fragment in engineering education}

Many engineering courses in new product development focus on teaching a methodology such as Design Thinking or on the project result at the end of a course. While students might be able 
to successfully apply methods and develop promising solution concepts during these courses, they oftentimes lack the required attitude and the procedural knowledge to repeat the action once they return to real environments. The concept presented in this paper seeks to complement these courses by focusing on the behavior of students in order to enable them to apply their methods knowledge and technical skills beyond the academic safe harbor.

Classical soft skill workshops have tried to close the gap focusing on the behavior of participants. As the workshops use artificial and simplified scenarios to showcase new approaches, the participants have difficulties transferring the behavioral learnings to their daily routines.

\section{Methodology}

\section{Course Design}

The course design in this paper follows the approach Constructive Alignment that was first introduced by John Biggs in 1996 and was since then applied in educational concepts throughout the world (Biggs, 1996, 2011). As illustrated in Figure 1, it says that when designing an educational activity, one should first define the learning goals of the activity. Based on these one must derive targeted methods for teaching and self-study and define appropriate methods for the examination of the defined learning goals.

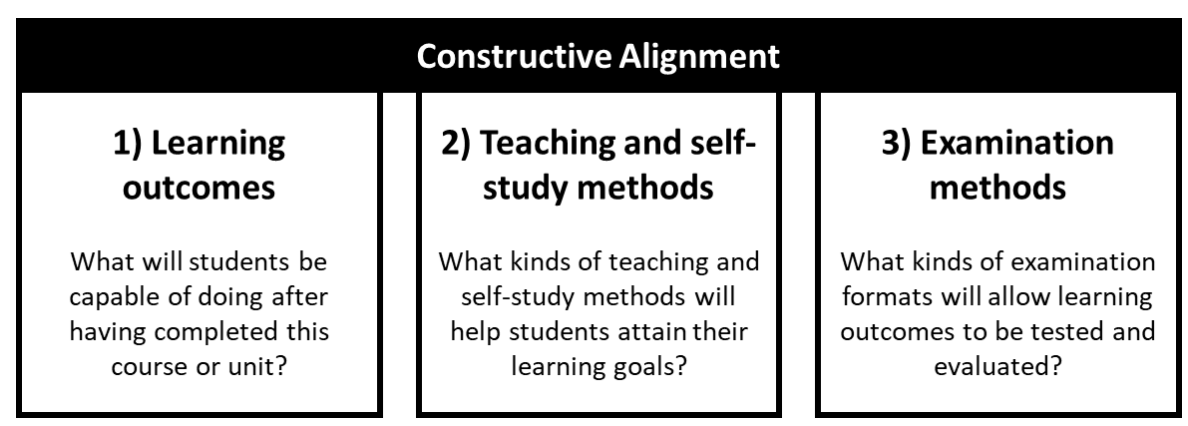

Figure 1. Three pillars of constructive alignment for design of teaching formats.

Based on the course design approach three research questions are derived:

- RQ1: Which set of learning outcome statements describe the requirements for behavioral competences of future engineers in new product development?

- RQ2: Which course elements can be used to push students to explore, enhance and train the targeted behavioral aspects?

- RQ3: How can we assess the effect of our course on the desired competencies?

\section{Research Methodology}

In order to answer the questions Design Science Research by Hevner and Chatterjee (2010) is used. Global requirements are deduced from the local environment and backed by literature to ensure relevance and rigor. For that an intensive literature review is conducted on which skills, attitudes and behavior have been defined in research on future engineering education and its alignment with innovative environments. Results are aligned with insights gathered from interviews with local stakeholders in engineering education, their experiences and best practices to define a set of matching learning outcome statements for the novel concept. The educational concept is systematically generated top-down to match the learning outcomes, integrated into a local innovation course and empirically tested. Observations and new questions are derived and integrated into the concept as well as the research. 


\section{Definition of Learning Outcomes}

The goals of entrepreneurial education differ throughout literature and the measurement of soft learning outcomes such as mindset presents a significant challenge. Since a person's mindset, attitude and skills are expressed through their behavior, behavioral indicators can be used as learning targets. Requirement data collected from a literature review and interviews with local stakeholders was clustered by keywords to identify a set of required transdisciplinary behavioral aspects for future engineers in an innovation context (see Figure 2). (Burnett \& Evans, 2016; Byers et al., 2013; Crawley, 2011; Davis et al., 2016; Dweck, 2009; Dyer et al., 2019; Elmuti et al., 2012; Gemino et al., 2018; Institute for the Future \& Dell Technologies, 2017; Ireland, 2003; Lackéus, 2015; Rae \& Melton, 2016; Schar, 2011; Seelig, 2012; Sethi, Smith, \& Park, 2001; Yoder et al., 2013)

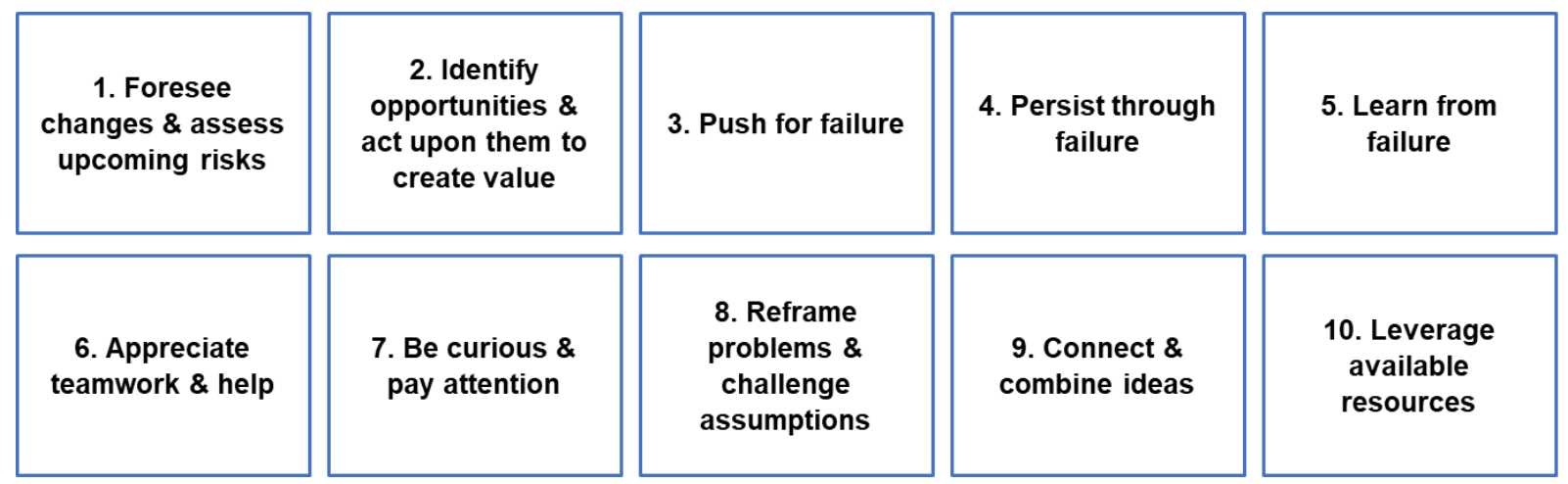

Figure 2. Learning outcome statements defined as behavioural indicators that specify the behavioural competences that engineers shall develop during their education in addition to classical engineering skills.

1. Foresee changes $\&$ assess upcoming risks refers to the anticipation of economic, social or technological changes which is necessary to stay flexible and adaptable. Future engineers must anticipate changes and assess whether these inherit potential for value creation or pose a risk to the current system. They need to predict changes induced by new technologies and assess the societal, ecological and economic consequences.

2. Identify opportunities \& act upon them to create value focuses on the proactive and responsible management of opportunities and risks. In a competitive and dynamic environment, changes must not only be foreseen and assessed but also exploited to increase benefit and reduce damage.

3. Push for failure is especially relevant in uncertain and dynamic environments. Testing ideas early, often and repetitively unmasks false assumptions and reduces the risk of malinvestments.

4. Persist through failure refers to the way failure is dealt with. Valuable output can only be achieved through perseverance. Engineers must know that value creation is a process, that they must listen to the feedback of the user and must be open for the unexpected.

5. Learn from failure refers to the creator's perspective on failure. Dropping ideas, adapting to user wishes and correcting assumptions, approaches or even a vision is often necessary when failure occurs. The engineer must know that every iteration towards the final concept is part of the learning process.

6. Appreciate teamwork $\&$ help is essential in complex environments that require cooperation among disciplines and personalities. This means accepting and actively seeking other people's ideas and opinions and being able to communicate beyond disciplines. Change agents acknowledge their own limitations and appreciate help.

7. Be curious \& pay attention is a necessary condition to foresee changes, accept failure and not miss important details. Observing the environment and understanding 
surrounding systems is crucial. Opportunities to create value are likely to occur when one pays attention to the environment and its details.

8. Reframe problems \& challenge assumptions refers to reducing bias, questioning the status quo, and thinking outside the box. When assumptions are scrutinized, hidden insights on the object of value creation can be generated. This requires empathy and both cognitive and emotional abstraction.

9. Connect \& combine ideas focuses on consolidating perspectives and creating win-win situations. The disciplines in an interdisciplinary team can merge their disciplinary approaches to create new solutions by association. This takes creativity and imagination.

10. Leverage available resources means acquiring necessary resources while considering and reinterpreting what can be accessed fast and cheap. Assessing which resources are really needed, where to get them, and persuading people to grant access takes imagination and experience.

This set of behavioral indicators serves as comprehensive learning outcome describing the requirements for behavioral competences of future engineers in new product development.

\section{Educational Concept}

When designing means to foster behavior there are two alternative strategies, that should be considered: Firstly, a setting can be created which inherently favors and indirectly fosters the desired behavior. Secondly, requirements and tasks can be posed to participants that directly demand specific actions that match the behavior. This concept combines both strategies resulting in a rigid framework with few internal structure and predefined processes.

On a story level, New Product Development (NPD) and Entrepreneurship serves as the narrative for the course. The task is as follows: participants from various disciplines need to form teams, identify and understand problems in their environment, generate and validate solution concepts including a Minimum Viable Product, and create a viable business concept. In comparison to other courses on NPD and Entrepreneurship this concept presents a new and unique approach to engineering education due to four aspects:

\section{Focus on Student Behavior instead of Methodological and Technical Skills}

The present educational concept for a university course that is targeted on facilitating the specified behavior assumes that the behavioral competence is dependent on the person and the

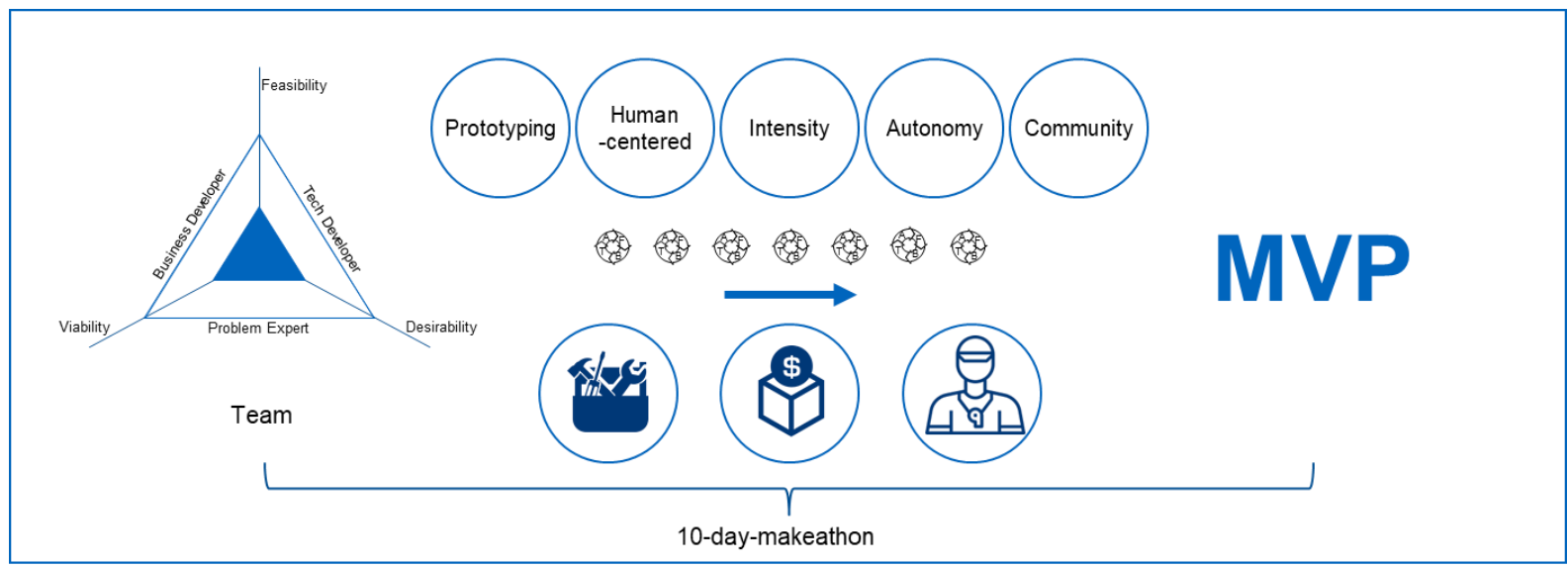

Figure 3. The educational concept: student teams need to develop an MVP within 10 days while being supported through infrastructure, prototyping budget and coaching. They apply an iterative, humancentred prototyping methodology with high intensity and autonomy while sourcing a community of talents and experts. 
surrounding context. The person itself is determined by its (genetic) predisposition, which is assumed to be static, and its experience, which changes over time. The course therefore seeks to set an artificial context in which the participants are provoked and yet able to show the defined behavior. Making new experiences within the course shall augment the participants' behavior in a way that they can show new (re-)actions in real environments after the course.

\section{High Responsibility and Autonomy for the Participants}

Five central principles were established that lay the foundation of the course concept to create situations during the course that require participants to exercise and show the defined behavior: intensity, autonomy, community, human-centeredness and prototyping.

In order to push for such situations and experiences, a rigid frame with few obligations was defined that provides the necessary feeling of safety while creating pressure on the inside. On a structural level, setting the frame as a competitive 10-day makeathon, in which participants work on real problems and need to pitch their ideas to the public on the last day, creates intensity. Peer-rated applications as well as audience and jury-voted prizes on the last day increase the pressure. Once a day every team is interrogated by expert coaches on the approach and progress of their project. Teams are sought to follow a human-centered approach and stay in close contact with potential users and customers. Since prototyping is the only methodological obligation participants can choose their actions freely during the course. From the choice of the application material to the choice of team members, the choice of a problem to work on, and a methodology to do so - participants are autonomous to choose their actions. Yet they need to take full responsibility.

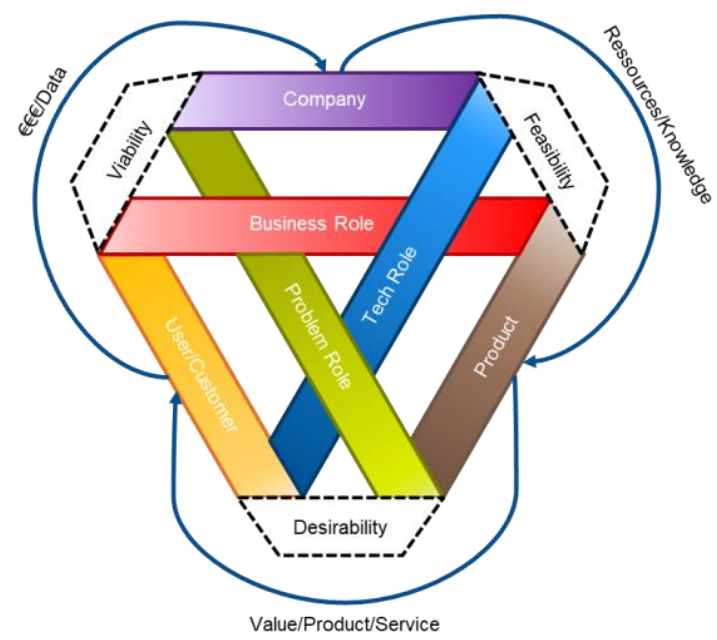

Figure 4. Team role model showing the interplay between responsibilities, communication interfaces, and success criteria. The blue arrows indicate the necessary value streams in the business model.

\section{Team Role Model ensures Interdisciplinary Collaboration}

In order to coordinate the team members and distribute responsibilities, a team role model was developed, which is illustrated in Figure 4. While the model contains three roles - tech business and problem - a role can be filled by one or more team members. The tech role is responsible for building the product. The business role is responsible for maintaining the company. And the problem role is responsible for understanding and satisfying the customer and/or user. The problem and tech roles need to communicate to make sure that the product provides a value for the customer and/or user (desirability). The problem and business roles need to communicate to make sure that the customer willingness to pay suffices to match the costs of the company (viability). Lastly, the business and tech roles need to communicate to make sure the company can provide the necessary resources and skills to build the product (feasibility). The exchange 
both with team members from other disciplines and with colleagues from the same discipline but other teams seeks to enhance collaboration and competition in the community.

\section{Prototyping Methodology induces Intensity}

The methodological part of the framework comprises an iterative, human-centered prototyping approach which bases on the Design Thinking model by Uebernickel et al. (2015). Its macro process defines seven prototype stages facilitating strategic decisions during the development phase. The micro process helps students to structure their operational tasks in prototyping by following a Frame-Build-Test-Act cycle. The methodology combines agile and lean aspects and seeks to support students with and without prior experience to create value and internalize the desired behavior. A detailed explanation of the methodology is presented in Pacheco et al. (2020, in review for NordDesign 2020). The value created during the course is assessed using the criteria desirability, feasibility and viability with respect to the generated solution concepts.

In the end the course elements can be matched to the target behavior. A subset of elements is depicted in Figure 5.

\begin{tabular}{|l|c|c|c|c|c|c|c|c|c|c|}
\hline & \multicolumn{7}{c|}{ Learning Outcome } \\
\cline { 2 - 12 } & 1 & 2 & 3 & 4 & 5 & 6 & 7 & 8 & 9 & 10 \\
\hline $\begin{array}{l}\text { Team Role Model \& } \\
\text { Interdisciplinary Networking }\end{array}$ & & & & & & $\bullet$ & & $\bullet$ & $\bullet$ & $\bullet$ \\
\hline Daily Q\&A Coaching Sessions & & $\bullet$ & $\bullet$ & $\bullet$ & $\bullet$ & & & $\bullet$ & $\bullet$ & \\
\hline $\begin{array}{l}\text { Workshop Disruption Fields \& } \\
\text { Trendanalysis }\end{array}$ & $\bullet$ & $\bullet$ & & & & & $\bullet$ & $\bullet$ & & \\
\hline Early Prototyping & & & $\bullet$ & $\bullet$ & $\bullet$ & & & & & $\bullet$ \\
\hline
\end{tabular}

Figure 5. Matching of an example set of course elements and learning activities to learning outcomes. The first row specifies the ten behavioural indicators. The first column shows a subset of course aspects. The dots in the matrix shows which activities and elements foster which behaviour.

\section{Field Testing and Evaluation}

\subsection{Course Description}

The educational concept was employed and tested during the tenth edition of the university course Think.Make.Start. (TMS) at Technical University of Munich in fall 2019 with 41 master students. The students had to apply for the course and were pre-selected in a peer-review process. Disciplines ranged from mechanical and electrical engineering, computer science and biomedical engineering to business, architecture and design. The participants formed eight teams with one Problem Expert each, one or two Business Developers, and two or three Tech Developers. The students were located in a large space with multiple rooms and 24/7 access. They had access to a high-tech workshop nearby, a technology library with standard hardware parts, and were provided with $400 €$ budget per team to buy supplies for prototyping. The participants were coached by methodological, technical and business experts, who were available for feedback from 9am to 5pm. Additional theory input was given on request. Every team had one Q\&A session per day with the coaches to answer questions regarding the progress of the project. On the last day the teams present their results to the public to win three prizes for the most popular idea, the most sophisticated prototype and the most promising business concept. 
An overview of the course projects is provided at www.thinkmakestart.com. A detailed example of individual team activities is published in Martins Pacheco et al. (2020).

\subsection{Test Design}

In order to evaluate the learning goals of the course and assess the learning progress of the students, one technology and two methodology coaches filled in a questionnaire every day (starting on day three) for every team after the Q\&A session, in which they assessed whether the respective team had shown each of the ten behavioral aspects or not. Questions were stated in the following form: „The team was able to [behavioral indicator]." A Likert scale was used as follows: (1) - strongly disagree, (2) - disagree, (3) - neutral, (4) - agree, (5) - strongly agree. Answers below (3) would indicate that the team did not adequately show the behavior. (3) was a neutral rating and all numbers above were positive ratings for the team on this indicator. Additionally, the coaches could reply with No Answer (N.A.), if they didn't see the indicator as assessable in that situation. As acceptance criteria the concept was said to be effective if a team continuously showed the desired behavior throughout the course with a rating greater than (3).

\subsection{Results}

Due to three coaches rating eight teams on ten behavioral aspects there were 240 datapoints collected every day. The data was plotted for every team, behavioral aspect and coach and analyzed in various ways. Figure 3 gives an overview of the behavior team ratings.
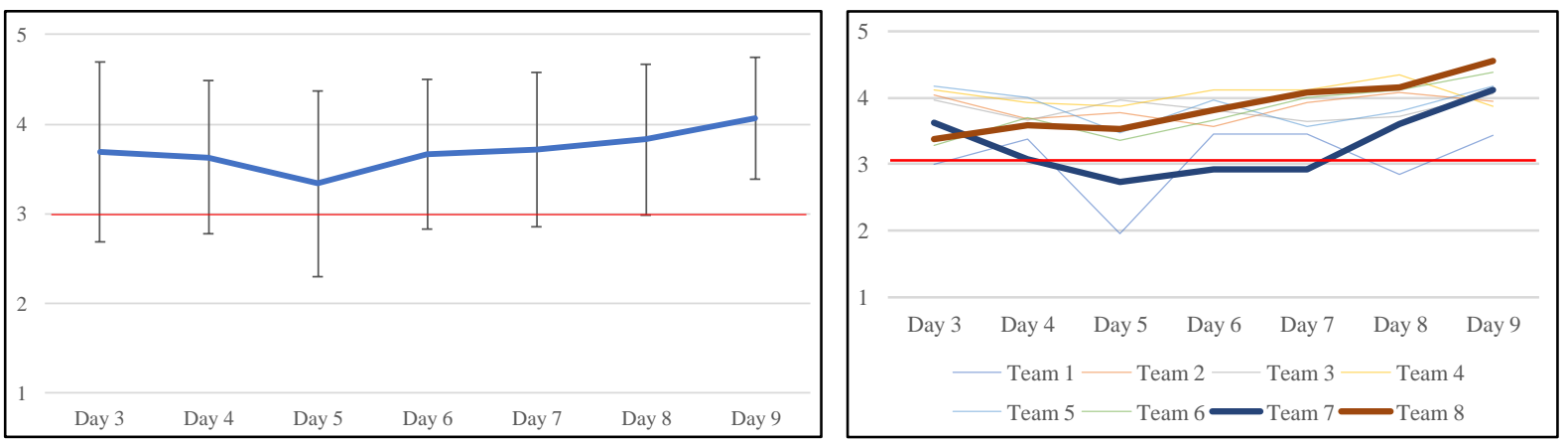

Figure 3. Assessment of team behaviour throughout the course, averaged over examiners, teams and behavioural aspects (left) and divided by teams (right). A value larger than (3) means that the behaviour was shown (red line). In the left image the blue line depicts the average while the black brackets show the standard deviation.

\subsection{Discussion}

\section{Observed Team Behavior}

According to the observations, $75 \%$ of the teams showed at least a subset of the desired behavior every day throughout the course (comp. Figure 3). A more detailed comparison of the data shows that there were differences among indicators. For example, indicator 10 (leverage available resources) was observed in every team almost every day with a rating of 3 to 5 while indicator 8 (reframe problems \& challenge assumptions) was rated neutral especially in the beginning of the course. There were also differences between teams. Some teams were continuously rated higher than others, which is visible due to an offset of the performance curves. According to the coaches these teams included team members with previous entrepreneurial experience and mindset. At this point it is difficult to say, whether the behavior was caused or enhanced by the course or if it was due to prior education or preconditioning. To answer this question a more complex evaluation with a pre-post test would be necessary. While 
most teams had a steady performance over the course of the event, two teams ( $7 \& 5$ ) showed fluctuation over time, which could have been caused by team conflicts dominating the actions or a loss of motivation due to negative feedback. The local minima on day 5 can be correlated to the mid-term presentation with external feedback, which is on the same day in the afternoon. Oftentimes teams spend the day on getting their project presentable and neglect challenging their ideas. The external pressure might push students back into their routines, which would be a positive indication for the course elements helping them to explore the desired behavior during the other days. Overall there seems to be a slight increase in the desired behavior over the course of the event. This could mean that the participants get used to the desired behavior during the event and internalize it.

\section{Limitation of the Study}

The quality criteria of empirical research with respect to this evaluation are validity, reliability and objectivity. While assessing the performance of student behavior through coach observations seems valid, the reliability and objectivity are limited. Due to personal interactions and connections between coaches and participants, there is a strong bias. Although there were three coaches from different disciplines that rated the teams independently, the data is not completely objective. Reliability might also be limited by the vague formulation of behavioral aspects. The performance ratings of coaches different for a certain team and aspect. As the understanding of the indicators may vary between coaches, repeatability is limited. Another limiting factor is the observability of the teams. As they could change the rooms at any time and autonomously define and prioritize tasks, the coaches did not observe all teams with the same intensity. Sometimes the observations were limited to the Q\&A sessions. At other times, a coach would spend a big portion of the day with a team in individual coaching.

On a higher level, six aspects must be discussed with respect to the choice and validity of the test itself. 1.) The assessment of behavior was limited to external assessment by coaches. When it comes to behavior the self-assessment and thus self-efficacy is another important factor, which was neglected in this study. A comprehensive analysis should incorporate both external and self-assessment. 2.) Measurement: maybe the coaches were not present when students showed a specific behavior. And even if a student did not show the desired behavior in the class, this does not necessarily mean that she cannot show it in other contexts. The type 2 error could skew the impression on the coaches. 3.) Accuracy: This study only addresses the team behavior and not individual activities and differences among team members. This is problematic as an individual assessment is necessary to evaluate the effectiveness of the course. In this study a good rating might be due to one team member performing very well, or multiple team members complementing each other. The result is therefore ambiguous. 4.) There was no control group. Some students might show the desired behavior in every course. Hence, a conclusion about the effect of course elements is difficult. 5.) The evaluation of behavior is limited to the duration of the course. There is no control of behavior after the course is over. Students may fall back into their previous behavior patterns. The long-term effectiveness of the concept is therefore not yet proven. 6.) The analyzed set of behaviors does not complete display all relevant competencies for future engineers as it ignores cognitive and technical elements. Therefore, it can only give a limited impression of the student's fitness with respect to innovation.

\section{Additional Improvements for Future Research}

In order to better evaluate the concept regarding its effectivity in fostering the desired learning goals, new ways of assessing behavior could be explored. The external assessment of teams could be detailed and complemented by an external assessment among team members and a self-assessment of every participant. One possible format is the learning portfolio. This would increase the objectivity as multiple assessments are compared and enable individual ratings. A 
detailed definition of the behavioral indicators could further improve the reliability by ensuring a common understanding.

In order to prove a difference between the behavior of students before, during and after the course, a more complex pretest-posttest study with a control group is recommended. For data collection there are various approaches including interviews or surveys. There approaches are usually time-consuming and expensive. A promising approach is evidence-based assessment or stealth assessment in virtual scenarios as a digital and automatic assessment is inherently objective and reliable.

\section{Conclusion}

This work derives a set of ten behavioral indicators, that describe the additional requirements that engineers need to fulfill in order to succeed in an increasingly uncertain and dynamic environment. Based on the assumption that typical behavior can be altered through new experiences, a novel educational concept for a ten-day university block course is presented, that systematically pushes participants to show, test and train the desired behavior during the format. The concept is tested in a practical course at Technical University of Munich with 41 interdisciplinary students. The learning goals are evaluated by the coaches using questionnaires. While the data itself suggests that the proposed concept does successfully foster the specified behavior, the way of data collection and learning assessment is biased and not scalable. It needs a cheap, objective and reliable assessment approach in order to scientifically evaluate the behavior of the participants and subsequently the effectiveness of such the educational concept.

\section{References}

Bennett, N., \& Lemoine, J. (2014). What VUCA really means for you. Harvard Business Review, 92(1/2).

Biggs, J. (1996). Enhancing teaching through constructive alignment. Higher education, 32(3), 347-364.

Biggs, J. B. (2011). Teaching for quality learning at university: What the student does. McGrawhill education (UK).

Burnett, W., \& Evans, D. J. (2016). Designing your life: How to build a well-lived, joyful life: Knopf.

Böhmer, A., Richter, C., Hostettler, R., Schneider, P., Plum, I., Böhler, D., ... others (2016). Think. Make. Start. - an agile framework. In DS 84: Proceedings of the DESIGN 2016 14th International Design Conference.

Byers, T., Seelig, T., Sheppard, S., \& Weilerstein, P. (2013). Entrepreneurship: Its role in engineering education. The Bridge, 43(2), 35-40.

Crawley, E. F., Malmqvist, J., Lucas, W. A., \& Brodeur, D. R. (2011). The CDIO syllabus v2. 0 . An updated statement of goals for engineering education. In Proceedings of 7 th international CDIO conference, Copenhagen, Denmark.

Davis, M. H., Hall, J. A., \& Mayer, P. S. (2016). Developing a new measure of entrepreneurial mindset: Reliability, validity, and implications for practitioners. Consulting Psychology Journal: Practice and Research, 68(1), 21-48. https://doi.org/10.1037/cpb0000045

Dweck, C. S. (2009). Developing Talent Through a Growth Mindset. Olympic Coach, 21(1).

Dyer, J., Gregersen, H., \& Christensen, C. M. (2019). Innovator's DNA, Updated, with a New Preface: Mastering the Five Skills of Disruptive Innovators. Harvard Business Press. 
Elmuti, D., Khoury, G., \& Omran, O. (2012). Does entrepreneurship education have a role in developing entrepreneurial skills and ventures' effectiveness? Journal of Entrepreneurship Education, 15, 83.

Gemino, A., Roche, B., \& Lubik, S. (2018). Mindset Matters: Encouraging an Entrepreneurial Mindset in K-12 Curriculum.

Hevner, A., \& Chatterjee, S. (2010). Design Science Research in Information Systems. In A. Hevner \& S. Chatterjee (Eds.), Integrated Series in Information Systems. Design Research in Information Systems (Vol. 22, pp. 9-22). Boston, MA: Springer US. https://doi.org/10.1007/978-1-4419-5653-8_2

Institute for the Future, \& Dell Technologies (2017). The Next Era of Human Machine Partnerships: Emerging Technologies' Impact on Society \& Work In 2030.

Ireland, R. (2003). A Model of Strategic Entrepreneurship: The Construct and its Dimensions. Journal of Management, 29(6), 963-989. https://doi.org/10.1016/S01492063(03)00086-2

Lackéus, M. (2015). Entrepreneurship in education: What, why, when, how. Entrepreneurship 360. Background Paper: Paris: OECD.

Leifer, L. (2012). ME310 Global - New Product Design Innovation: Global network of designers, engineers and innovators challenging complex real-world problems.

Martins Pacheco, N.M., Behrenbeck, J., Tariq, B., Vazhapilli Sureshbabu, A., Zimmermann, M. (2020) A role-based prototyping approach for human-centered design in fuzzy frontend scenarios, accepted for: Proceeding of NordDesign Conference 2020, 11-14.8.2020

National Academy of Engineering. (2004). The Engineer of 2020. Washington, D.C.: National Academies Press. https://doi.org/10.17226/10999

Rae, D., \& Melton, D. (2016). Developing an Entrepreneurial Mindset in US Engineering Education: the KEEN project. Journal of Engineering Entrepreneurship, 7, 1-16.

Schar, M. F. (2011). Pivot thinking and the differential sharing of information within new product development teams: Stanford University.

Seelig, T. (2012). In Genius: A crash course on creativity: Hay House, Inc.

Sethi, R., Smith, D. C., \& Park, C. W. (2001). Cross-Functional Product Development Teams, Creativity, and the Innovativeness of New Consumer Products. Journal of Marketing Research, 38(1), 73-85. https://doi.org/10.1509/jmkr.38.1.73.18833

Uebernickel, F., Brenner, W., Pukall, B., Naef, T., \& Schindlholzer, B. (2015). Design Thinking: Das Handbuch (Erste Auflage). Frankfurt am Main: Frankfurter Allgemeine Buch.

Van Stel, A., Carree, M., \& Thurik, R. (2005). The Effect of Entrepreneurial Activity on National Economic Growth. Small Business Economics, 24(3), 311-321. Retrieved from http://www.jstor.org/stable/40229425

World Economic Forum (2016). The future of jobs: Employment, skills and workforce strategy for the fourth industrial revolution. In Global Challenge Insight Report, World Economic Forum, Geneva.

Yoder, J.-D., Kleine, R., Carpenter, D., \& Fry, C. (2013). Spreading the fire: Broadening faculty support for the entrepreneurial mindset. In Venture Well. Proceedings of Open, the Annual Conference. Symposium conducted at the meeting of National Collegiate Inventors \& Innovators Alliance. 